\title{
TITLE:
}

\section{Thermal desorption of helium from defects in nickel}

$\operatorname{AUTHOR}(\mathrm{S}):$

Cao, X.Z.; Xu, Q.; Sato, K.; Yoshiie, T.

\section{CITATION:}

Cao, X.Z. ... [et al]. Thermal desorption of helium from defects in nickel. Journal of Nuclear Materials 2011, 412(1): 165-169

\section{ISSUE DATE:}

2011-05

URL:

http://hdl.handle.net/2433/141835

\section{RIGHT:}

(c) 2011 Elsevier B.V.; この論文は出版社版でありません。引用の際には 出版社版をご確認ご利用ください。; This is not the published version. Please cite only the published version. 


\title{
Thermal desorption of helium from defects in nickel
}

\author{
X.Z. Cao $^{1,2}, \underline{\text { Q.Xu }^{1}}$, K. Sato ${ }^{1}$, T. Yoshiie ${ }^{1}$ \\ 1) Research Reactor Institute, Kyoto University, Osaka 590-0494, Japan \\ 2) Institute of High Energy Physics, Chinese Academy of Sciences, Beijing 100049, China
}

Research Reactor Institute, Kyoto University, Osaka 590-0494, Japan

[Corresponding Author]

Name $\quad$ : Qiu Xu

Postal address : Research Reactor Institute, Kyoto university, Kumatori-Cho, Sennan-gun, Osaka, 590-0494, Japan.

Telephone number $\quad$ : +81-724-51-2417

Fax number $\quad:+81-724-51-2620$

E-mail address $\quad: \underline{x u @ r r i . k y o t o-u . a c . j p ~}$ 


\title{
Thermal desorption of helium from defects in nickel
}

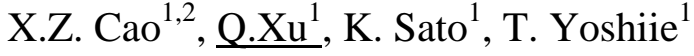 \\ 1) Research Reactor Institute, Kyoto University, Osaka 590-0494, Japan \\ 2) Institute of High Energy Physics, Chinese Academy of Sciences, Beijing 100049, China
}

\begin{abstract}
Helium atoms, introduced into materials by helium plasma or generated by the $(n, \alpha)$ nuclear reaction, have a strong tendency to accumulate at trapping sites such as vacancy clusters and dislocations. In this paper, the effects of dislocations, single vacancies and vacancy clusters on the retention and desorption of helium atoms in nickel were studied. Low energy (0.1-0.15 keV) helium atoms were implanted in nickel with vacancies or dislocations without causing any displacement damage. He atoms, interstitial-type dislocation loops, and vacancy clusters were also introduced with irradiation damage by $5.0 \mathrm{keV}$ helium ions. Helium thermal desorption peaks from dislocations, helium-vacancy clusters and helium bubbles were obtained by thermal desorption spectroscopy at $940 \mathrm{~K}$, in the range from 900 to $1370 \mathrm{~K}$, and at $1500 \mathrm{~K}$, respectively. In addition, a thermally quasi-stable state was found for helium-vacancy clusters.
\end{abstract}

Keywords:

helium, dislocation, vacancy, helium-vacancy clusters, helium bubbles, thermal desorption, dissociation energy 


\section{Introduction}

It is well known that helium bubbles in metals and alloys drastically alter the mechanical properties, potentially blistering surfaces and embrittling materials, even at low concentrations [1-3]. In nuclear reactor materials, helium atoms are generated by $(n, \alpha)$ nuclear reactions in the first wall, or introduced directly into plasma-facing materials by helium plasma in fusion reactors $[4,5]$. Helium has a strong tendency to precipitate in vacancy clusters and grain interiors [6]. The understanding of helium bubble formation and its effect on mechanical properties is a significant challenge associated with the development of long-lived and high-performance fusion reactor materials [7].

Helium atoms interact strongly with defects, and form a high density of helium bubbles [8-11]. Unfortunately, there are potentially many defects in the first wall materials of fusion reactors, such as dislocations, vacancy clusters and precipitates. These defects play a significant role in the trapping of helium atoms and the prevention of their long-range migration [12]. Unfortunately, the mechanism of interaction between helium atoms and defects remains unclear.

In order to investigate the behavior of helium atoms in nickel, helium ions were implanted with and without displacement damage at high and low energy, respectively. Helium retention and desorption by defects in nickel were investigated using thermal desorption spectroscopy (TDS) and transmission electron microscopy (TEM). Positron annihilation spectroscopy (PAS) was also used to identify intentionally-introduced defects in the specimens.

\section{Experimental procedures}

The experimental procedures employed for preparation of specimens are shown in Fig.1. Pure nickel (99.99\%) specimens with $0.1 \mathrm{~mm}$ in thickness were annealed at $1223 \mathrm{~K}$ for 1 hour in high vacuum conditions $\left(10^{-4} \mathrm{~Pa}\right)$. To introduce dislocations, well-annealed specimens were cold rolled to $10 \%$ of their original thickness at room temperature and then annealed at $673 \mathrm{~K}$ for 1 hour in a 
high vacuum to annihilate vacancies and vacancy clusters. To introduce Frenkel pairs, electron irradiation at $100 \mathrm{~K}$, using an electron linear accelerator (LINAC) at the Research Reactor Institute of Kyoto University was performed with an accelerating voltage of $30 \mathrm{MeV}$ and an electron fluence of $4 \times 10^{22} \mathrm{e}^{-} / \mathrm{m}^{-2}$.

PAS was used to investigate the structures and density of defects by measuring the lifetime of positrons annihilation at defects. The positron lifetime spectrometer had a time resolution of $190 \mathrm{ps}$ (FWHM), and each spectrum was accumulated to a total of $1 \times 10^{6}$ counts or more. To discriminate annihilation between bulk and defects components, the lifetime spectrum was decomposed into two components, short lifetime $\tau_{1}$ and long lifetime $\tau_{2}$, based on the two-state trapping model, after subtracting the radioactive source and background components and deconvoluting a time-resolution function [13]. All measurements were performed at room temperature.

Helium implantation was carried out using a mono-energetic helium ion beam at room temperature in a vacuum of $8.0 \times 10^{-6} \mathrm{~Pa}$. The helium ions were collimated and mass-analyzed, and the beam flux was monitored by a faraday cup. Two types of helium introduction were performed. The first was low energy implantation $(0.1-0.15 \mathrm{keV})$ to introduce helium atoms without causing displacement damage at dislocations or Frenkel pairs in nickel. Helium atoms were accumulated to $5.0 \times 10^{19} \mathrm{He}^{+} / \mathrm{m}^{2}$ with a flux of $5.0 \times 10^{15} \mathrm{He}^{+} / \mathrm{m}^{2} \mathrm{~s}$. The second was high energy irradiation (5.0 $\mathrm{keV}$ ) to $5.0 \times 10^{19} \mathrm{He}^{+} / \mathrm{m}^{2}$ to introduce defects and helium atoms simultaneously into well-annealed nickel.

TDS was performed to investigate helium retention and desorption from trapping sites in cold rolled specimens and electron irradiated specimens after low energy helium ion implantation, and well-annealed specimens after high energy helium irradiation. The temperature was changed from 293 to $1523 \mathrm{~K}$ using an infrared radiation heater. Helium desorption during heating was monitored by a quadruple mass analyzer in a vacuum of $10^{-6} \mathrm{~Pa}$.

\section{Results and discussion}


The defect structures of the specimens were investigated using PAS for each experimental procedure. The lifetimes of positron annihilation with the presence of defects are shown in Table 1. The long lifetime component $\tau_{2}$ in cold rolled specimens decreased from 164.0 to 128.8 ps after annealing at $673 \mathrm{~K}$ for 1 hour. Although this was slightly larger than the value of 119 ps at dislocation lines in nickel [11], we assigned it to the annihilation of positrons at dislocation networks, because the vacancy clusters were nearly eliminated by annealing at $650 \mathrm{~K}$ [14]. The formation of dislocation networks was confirmed by TEM, as shown in Fig.2. After annealing, the long lifetime with an intensity $\mathrm{I}_{2}$ of $85.2 \%$ indicated that positrons were mainly annihilated at dislocation lines. The mean lifetime $\tau_{\mathrm{m}}$ of electron irradiated specimens was $174.1 \mathrm{ps.}$ As this value was the same as the lifetime of positron annihilation at single vacancies in nickel [15-17], we concluded that these specimens contained primarily single vacancies. The change in lifetimes and intensities after helium ion implantation was insignificant.

Helium thermal desorption spectra are shown in Fig.3. The desorption spectra in Fig. 3(a) is from cold rolled specimens (containing dislocations) after implantation by $0.1 \mathrm{keV}$ helium ions to $5 \times 10^{19} \mathrm{He}^{+} / \mathrm{m}^{2}$. The desorption spectra in Fig. 3(b) is from electron irradiated specimens after implantation by $0.15 \mathrm{keV}$ helium ions to $5.0 \times 10^{19} \mathrm{He}^{+} / \mathrm{m}^{2}$. The desorption spectra in Fig. 3(c) is from a well-annealed specimen after irradiation by $5.0 \mathrm{keV}$ helium ions to $5 \times 10^{19} \mathrm{He}^{+} / \mathrm{m}^{2}$. Peak A in (a) is a clear helium desorption peak at $940 \pm 10 \mathrm{~K}$. Peaks in (b) are in the temperature range from 900 to $1080 \mathrm{~K}$ and are separated into two peaks, with a broad Peak $\mathrm{B}_{1}$ at $950 \pm 20 \mathrm{~K}$ and a relatively sharp Peak $B_{2}$ at $1015 \pm 15$ K. Five helium desorption peaks can be observed in (c), after heating to $1523 \mathrm{~K}$ : Peak $\mathrm{C}_{1}$ at $950 \pm 15 \mathrm{~K}$, Peak $\mathrm{C}_{2}$ at $1050 \pm 20 \mathrm{~K}$, Peak $\mathrm{C}_{3}$ at $1200 \pm 20 \mathrm{~K}, \mathrm{Peak}_{4}$ at $1250 \pm 12 \mathrm{~K}$ and Peak $\mathrm{C}_{5}$ at $1480 \pm 30 \mathrm{~K}$.

The helium desorption peaks with a constant heating rate correspond to the release of helium atoms from different trapping sites [18]. From the first-order desorption mechanisms, the dissociation rate $L(T)$ of helium from defects is expressed as 


$$
L(T)=\mathrm{d} N / \mathrm{d} t=-N v \exp \left(-E_{d} / k_{B} T\right),
$$

where $N$ is the concentration of helium atoms trapped by defects at an absolute temperature $T, v$ is the attempt frequencies assumed to be on the order of the Debye frequency, $10^{13} \mathrm{~s}^{-1}, E_{d}$ is the dissociation energy of helium from defects and $k_{B}$ is the Boltzmann constant. The relationship among desorption peak temperature $T_{p}$, heating rate $R$ and dissociation energy $E_{d}$ was derived as follows $[9,19]$.

$$
\ln \left(R / T_{p}^{2}\right)=-E_{d} / k_{B} T_{p}+\ln \left(v k_{B} / E_{d}\right) .
$$

As the heating rate $R$ was fixed at $1 \mathrm{~K} / \mathrm{s}$ in these experiments, the dissociation energy (in electron volts) for an average group of traps was estimated as [10],

$$
E_{d}=0.0029 T_{p} .
$$

The dissociation energies of helium atoms from defects were estimated by Eq. (3). These were $2.73 \pm 0.03 \mathrm{eV}$ for Peak A $\left(\mathrm{He}_{n} \mathrm{D}\right), 2.76 \pm 0.06 \mathrm{eV}$ for Peak $\mathrm{B}_{1}, 2.94 \pm 0.04 \mathrm{eV}$ for Peak $\mathrm{B}_{2}, 2.76 \pm 0.04 \mathrm{eV}$ for Peak $\mathrm{C}_{1}, 3.05 \pm 0.06 \mathrm{eV}$ for Peak $\mathrm{C}_{2}, 3.48 \pm 0.06 \mathrm{eV}$ for Peak $\mathrm{C}_{3}, 3.63 \pm 0.03 \mathrm{eV}$ for Peak $\mathrm{C}_{4}$ and $4.35 \pm 0.06 \mathrm{eV}$ for Peak $\mathrm{C}_{5}$.

The helium desorption peak, Peak A, was assigned to dissociation from dislocation networks $\left(\mathrm{He}_{n} \mathrm{D}\right)$, because these were the sole defects reserved before low energy helium ions implantation. As the dissociation energy of Peaks $B_{1}$ and $C_{1}$ are close to the Peak $A$, these peaks maybe contributed mainly by the dissociation from dislocations. These dislocations were interstitial type dislocation loops formed by electron irradiation and $5.0 \mathrm{keV}$ helium ions irradiation. Peak $\mathrm{B}_{2}$ was assigned to dissociation from single vacancies $\left(\mathrm{He}_{\mathrm{n}} \mathrm{V}\right)$, because these were the main defects formed by electron irradiation. As the dissociation energy of Peak $C_{2}$ is close to the Peak $B_{2}$, the peak maybe contributed mainly by the dissociation from vacancies. After irradiated by $5.0 \mathrm{keV}$ helium ions, single vacancies remained at room temperature. Peaks $\mathrm{C}_{3}$ and $\mathrm{C}_{4}$ represented dissociation from helium-vacancy clusters $\left(\mathrm{He}_{\mathrm{n}} \mathrm{V}_{\mathrm{m}}\right)$. Peak $\mathrm{C}_{5}$ of the highest temperature was assumed to be the 
dissociation from helium bubbles.

In order to investigate Peaks $\mathrm{C}_{3}$ and $\mathrm{C}_{4}$ in more detail, a special thermal procedure was employed in the TDS experiments. Specimens were initially heated to a high temperature at a heating rate of $1 \mathrm{~K} / \mathrm{s}$, annealed at this temperature for 1 hour, and finally heated to $1523 \mathrm{~K}$ at the same heating rate. The annealing temperatures were chosen to be 1123 and $1223 \mathrm{~K}$, lower than the temperature of Peak $\mathrm{C}_{4}$ as shown in Fig.3(c). The heat treatment and the helium desorption results are shown in Fig. 4, with the heating procedure and helium desorption spectra with time shown on the right axis and left axis, respectively. Peaks $\mathrm{C}_{3}$ and $\mathrm{C}_{4}$ were clearly separated into two peaks. Peak $\mathrm{C}_{4}$ was obtained after annealing for $180 \pm 50 \mathrm{~s}$ at $1223 \mathrm{~K}$, as shown in Fig. 4(a), or from $1240 \pm 35$ K re-heating after annealing at $1123 \mathrm{~K}$ for 1 hour. Peak $C_{5}$ was also obtained at $1500 \pm 20 \mathrm{~K}$ after re-heating to $1523 \mathrm{~K}$. As there was a variety of helium-vacancy clusters, the helium atoms dissociated over a wide range of temperatures [20-24].

Specimens irradiated by $5.0 \mathrm{keV}$ helium ions to $5 \times 10^{19} \mathrm{He}^{+} / \mathrm{m}^{2}$ were also observed by TEM during heat treatments. The defect microstructures observed by TEM and shown in Figs. 5 and 6 are related to the heat treatments of Figs. 4(a) and (b), respectively. The heat treatments used in the experiments are shown below the TEM results. Figure 5(a) shows that interstitial type dislocation loops were formed by irradiation damage from $5.0 \mathrm{keV}$ helium ions at room temperature. The dislocation loops grow as shown in Fig. 5 (b) after heating to $1223 \mathrm{~K}$, and in Fig. 6(a) after heating to $1123 \mathrm{~K}$. As seen in Figs. 5(c), 6(b), and 6(c) the dislocation loops remained after annealing for 1 hour. However, almost no dislocation lines were observed after heating to $1263 \mathrm{~K}$ (Fig. 6(d)). Cavities were also observed, with an average size of nearly $10 \mathrm{~nm}$ in Fig. 5(b), $80 \mathrm{~nm}$ in Fig. 5(c), $20 \mathrm{~nm}$ in Figs. 6(b)-(c), and $30 \mathrm{~nm}$ in Fig. 6(d), but no cavities were observed in Fig. 6(a). The cavities mainly existed on dislocation lines. There was no obvious change in size for the large cavities between Figs. 6(b)-(d).

These results indicate that Peak $C_{3}$ was from the decomposition of small helium-vacancy 
clusters, which were not observed by TEM (Fig. 6(a)). Peak $\mathrm{C}_{4}$ was due to decomposition of more stable helium-vacancy clusters.

The thermal stability of a helium vacancy cluster is affected by the size of the cluster and the number of helium atoms trapped within it. We refer to the trapping sites of Peak $\mathrm{C}_{4}$ as a thermal quasi-stable state. Similar state was reported in several materials as iron, plutonium and tungsten $[10,23,25,26]$. It was reported that the ratio of helium/vacancy cluster for the relatively stable state in iron is a constant of 1.8. Helium-vacancy clusters with ratios above or below 1.8 are unstable and release helium atoms or vacancy at lower temperatures than quasi-stable state clusters. This model maybe used to verify the Peaks $C_{3}$ and $C_{4}$ are dissociated from the helium-vacancy clusters with high density helium atoms and from the thermally quasi-stable state, respectively.

Large cavities remained until $1263 \mathrm{~K}$, which must have been bubbles, and which corresponded to Peak $\mathrm{C}_{5}$ in Figs. 3 and 4 . The large bubbles in Fig. 5(c) were formed during annealing at $1233 \mathrm{~K}$ for $30 \mathrm{~min}$.

We assigned Peak $\mathrm{B}_{1}$ to helium desorption from dislocations because it was at nearly the same desorption temperature as that of the dislocation network. There was another possibility, however, that the temperature range indicated by the arrow in Fig. 3(b) was from $\mathrm{He}_{\mathrm{n}} \mathrm{V}$. Peak $\mathrm{B}_{1}$ represented the release of helium atoms from unstable helium-vacancy complexes, which was similar to the relationship between $\mathrm{C}_{3}$ and $\mathrm{C}_{4}$, if the formation of interstitial type dislocation loops by electron irradiation was less prominent. There was also the possibility that desorption in the temperature range indicated by the arrow in Fig. 3(c) was the release of helium atoms from variously $\mathrm{He}_{\mathrm{n}} \mathrm{V}_{\mathrm{m}}$ complexes.

\section{Conclusions}

Studies of helium desorption from nickel indicate that helium atoms were captured by 
dislocations and single vacancies during diffusion, even after the helium atoms were implanted at low energy and without irradiation damage, as from the helium plasma of fusion reactors. Interstitial types dislocation loops, vacancies and vacancy clusters were formed by irradiation with $5.0 \mathrm{keV}$ helium ions, and acted as trapping sites for helium atoms. Dislocation networks grown from interstitial type dislocation loops contributed to the formation of helium-vacancy clusters and promoted the formation of helium bubbles. A thermal quasi-stable state, with a constant ratio between helium atoms and vacancies, existed in the helium-vacancy clusters. The dissociation energy of helium atoms from various trapping sites was estimated from the temperatures of helium desorption spectra. 


\section{References}

[1] D. Kaminsky, S.K. Das, J. Nucl. Mater. $76 \& 77$ (1978) p 256

[2] R.E. Stoller, J. Nucl. Mater. 174 (1990) p 289.

[3] V.N. Chernikov, A.P. Zakharov, P.R. Kazansky, J.Nucl. Mater. 155/157 (1988) p 1142

[4] K. Morishita, R. Sugano, B.D. Wirth, T. Diaz de la Rebia, Nuclear Instruments and Methods in Physics Research B 202(2003), p 76-81

[5] N.M. Beskorovainy, B.A. Kalin, P.A. Platonov, I.I. Chernov. Structural Materials for Nuclear Reactors, Energoatomizdat, Moscow, 1995

[6] L.Ventelon, B.Wirth, C. Domain, J. Nucl. Mater. 351 (2006) p119-132

[7] E.E. Bloom, J. Nucl. Mater. 7 (1998) p 258

[8] R.Vassen, H.Trinkaus, P.Jung, Phys. Rev. B 44 (1991) 4206

[9] Donghua Xu, Brian D. Wirth, J. Nucl. Mater. 388 (2009) p 395-399

[10] K. Morishita, R. Sugano, B.D. Wirth, T. Diaz de la Rubia, Nucl. Inst. \& Meth. in Phys. Res. B 202 (2003) p 76-81.

[11] E. Kuramoto, T. Tsutsumi, K. Ueno, M. Ohmura, Y. Kamimura, Comput. Mater. Sci. 14 (1999) p 28-35

[12] T. Kawakami, K. Tokunaga, N. Yoshida, Fusion Engineering and Design 81 (2006) p 335-340

[13] W. Brandt, A. Dupasquier, Positron Solid-State Physics, North-Holland, Amsterdam, (1989) p 659.

[14] K. Sato, T. Yoshiie, T. Ishizaki, Q. Xu, Phys, Rev. B 75, (2007) 094109

[15] H. Ohkubo, Z. Tang, Y. Nagai, M. Hasegawa, T. Tawara, M. Kiritani, Mater. Sci. \& Engi. A 350 (2003) p 95-101.

[16] E. Kuramoto, H. Abe, M. Takenaka, F. Hori, Y. Kamimura, M. Kimura, K. Ueno, J. Nucl. Mater. 239 (1996) 54-60.

[17] H. Okazawa, T. Yoshiie, T. Ishizai, K. Sato, Q. Xu, Y. Satoh, Y. Ohkubo, and Y. Kawase, J. Nucl. 
Mater. 329-333 (2004) p 967-970

[18] E.V.Kornelsen, A.A. van Gorkum. Vacuum 31 (1981) p 99

[19] Donghua Xu, Brian D. Wirth, J. Nucl. Mater. 388 (2009) p 395-399

[20] H. Trinkaus, Radiat. Eff. 78 (1983) p 189

[21] W.D. Wilson, C.L. Bisson, M.I. Baskes, Phys, Rev. B 15 (1981) p 5616-5624

[22] H. Trinkaus, J. Nucl. Mater. 118 (1983) p 39-49

[23] B.Ao, X. Wang, W. Hu, J. Yang, J. Nucl. Mater. (2008), doi:10.1016/j.jnucmat.2008.09.034

[24] K. Morishita, R. Sugano, B.D. Wirth, J. Nucl. Mater. 323 (2003) 243-250.

[25] C.S. Becquart, C. Domain, J. Nucl. Mater. 385 (2009) 223-227

[26] Chu-Chun Fu, F. Willaime, Phy. Rev. B 72, 064117 (2005) 
Figure captions:

Fig.1. Preparation of specimens.

Fig.2. Dislocation networks in nickel, annealed at $673 \mathrm{~K}$ for 1 hour after cold rolling at room temperature.

Fig.3. Helium thermal desorption spectra for nickel from 293 to $1523 \mathrm{~K}$ with a fixed heating rate of 1 K/s. (a) implanted by $0.1 \mathrm{keV}$ helium ions to $5 \times 10^{19} \mathrm{He}^{+} / \mathrm{m}^{2}$ in cold rolled nickel, (b) implanted by $0.15 \mathrm{keV}$ helium ions to $5.0 \times 10^{19} \mathrm{He}^{+} / \mathrm{m}^{2}$ in electron irradiated nickel, and (c) irradiated by $5.0 \mathrm{keV}$ helium ions to $5 \times 10^{19} \mathrm{He}^{+} / \mathrm{m}^{2}$ in well-annealed nickel.

Fig.4. Helium thermal desorption and retention spectra in well-annealed nickel after helium irradiation by $5.0 \mathrm{keV}$ to $5 \times 10^{19} \mathrm{He}^{+} / \mathrm{m}^{2}$. Heating rate is $1 \mathrm{~K} / \mathrm{s}$, (a) was annealed at $1223 \mathrm{~K}$ for 1 hour, and (b) was annealed at $1123 \mathrm{~K}$ for 1 hour.

Fig.5. Microstructures in well-annealed nickel: (a) after irradiation by $5.0 \mathrm{keV}$ helium ions to $5 \times 10^{19}$ $\mathrm{He}^{+} / \mathrm{m}^{2}$, (b) heating to $1223 \mathrm{~K}$ with a rate of $1 \mathrm{~K} / \mathrm{s}$, (c) annealing at $1223 \mathrm{~K}$ for 30 minutes.

Fig.6. Microstructures in nickel after helium ion irradiation by $5.0 \mathrm{keV}$ to $5 \times 10^{19} \mathrm{He}^{+} / \mathrm{m}^{2}$ : (a) heating to $1123 \mathrm{~K}$ at a rate of $1 \mathrm{~K} / \mathrm{s}$, (b) annealing at $1123 \mathrm{~K}$ for 1 hour, (c) re-heating to $1223 \mathrm{~K}$, and (d) re-heating to $1263 \mathrm{~K}$. 
Table 1 Positron annihilation lifetimes in cold rolled and electron irradiated nickel.

\begin{tabular}{|c|c|c|c|c|c|}
\hline \multicolumn{2}{|l|}{ Procedure } & \multirow{2}{*}{$\begin{array}{c}\text { One component } \\
\tau_{\mathrm{m}}(\mathrm{ps})\end{array}$} & \multicolumn{3}{|c|}{ Two components } \\
\hline & & & $\tau_{1}(\mathrm{ps})$ & $\tau_{2}(\mathrm{ps})$ & $\mathrm{I}_{2}(\%)$ \\
\hline \multicolumn{2}{|c|}{ Well-annealed at $1223 \mathrm{~K}, 1$ hour } & $106.5 \pm 0.2$ & - & - & \\
\hline \multirow{3}{*}{ Cold rolled } & Cold rolled to $10 \%$ of thickness & $147.5 \pm 0.3$ & $70.2 \pm 8.9$ & $164.0 \pm 5.6$ & $82.5 \pm 2.8$ \\
\hline & Annealed at $673 \mathrm{~K}, 1$ hour & $116.3 \pm 0.2$ & $44.2 \pm 4.9$ & $128.8 \pm 1.0$ & $85.2 \pm 1.3$ \\
\hline & Implanted by $0.1 \mathrm{keV} \mathrm{He} e^{+}$ & $120.1 \pm 0.3$ & $55.8 \pm 7.9$ & $129.4 \pm 1.3$ & $87.4 \pm 2.4$ \\
\hline \multirow{2}{*}{$\begin{array}{l}\text { Electron } \\
\text { irradiated }\end{array}$} & Irradiated by electron at $100 \mathrm{~K}$ & $174.1 \pm 1.4$ & - & - & \\
\hline & Irradiated by $0.15 \mathrm{keV} \mathrm{He}{ }^{+}$ & $178.8 \pm 0.7$ & - & - & \\
\hline \multicolumn{2}{|c|}{ Thermal desorption to $1523 \mathrm{~K}$} & $107.4 \pm 0.2$ & - & - & \\
\hline
\end{tabular}


Fig.1. Preparation of specimens.

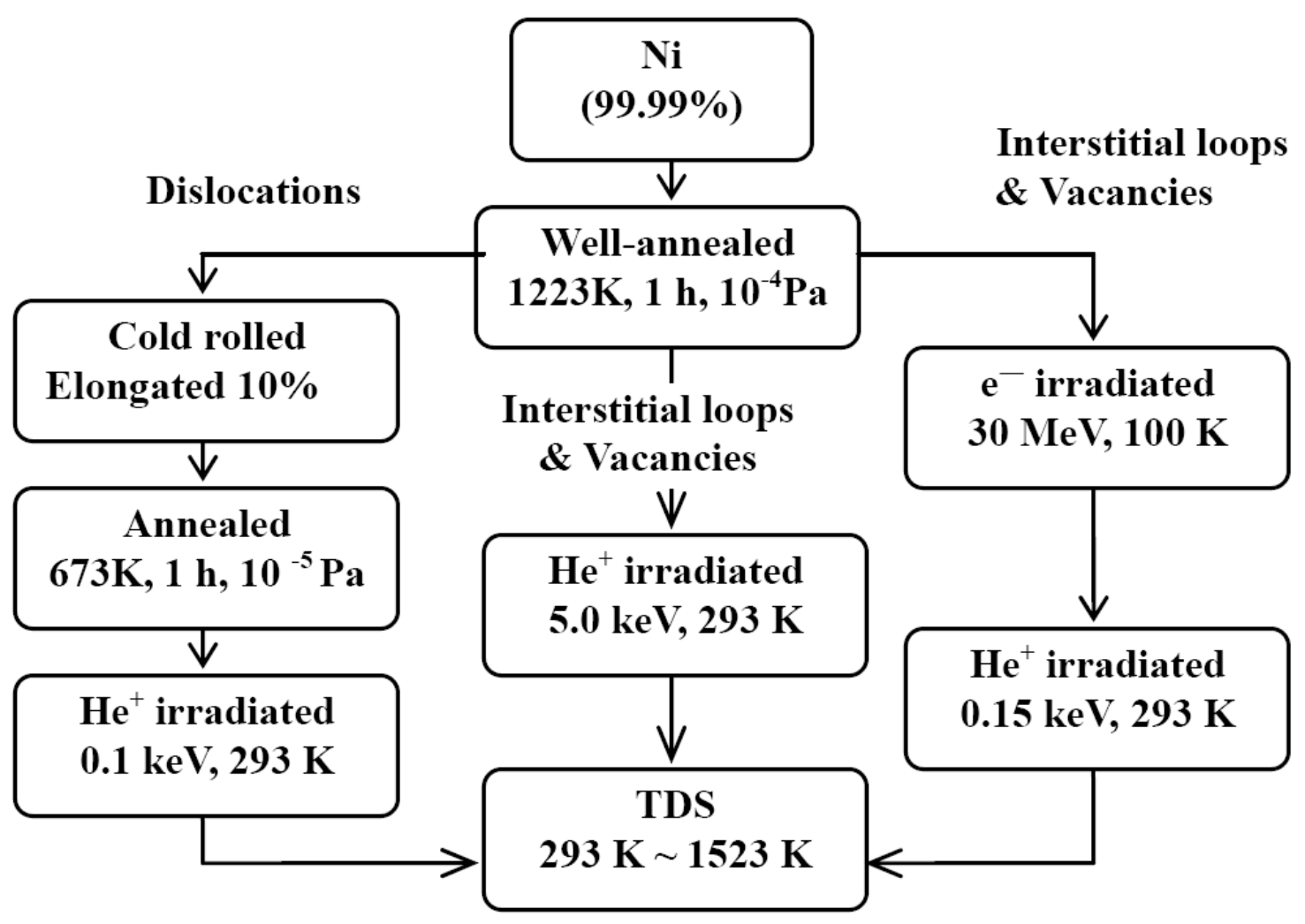


Fig.2. Dislocation networks in nickel, annealed at $673 \mathrm{~K}$ for 1 hour after cold rolling at room temperature.

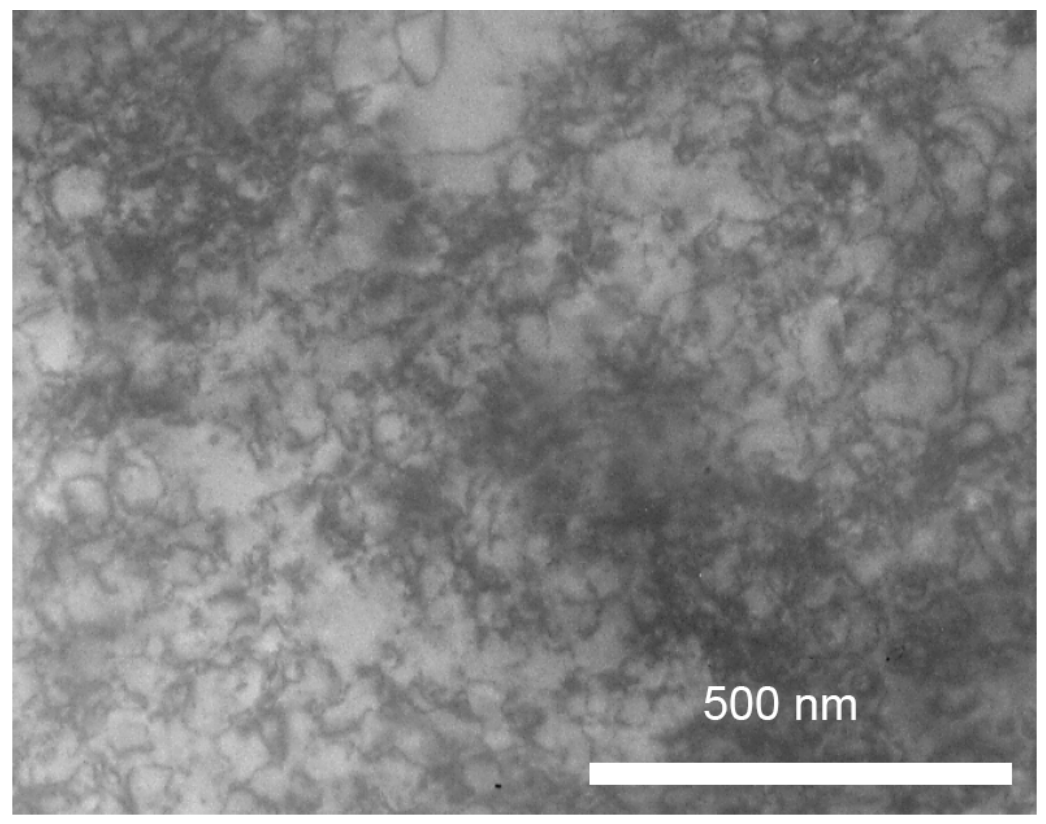


Fig.3. Helium thermal desorption spectra for nickel from 293 to $1523 \mathrm{~K}$ with a fixed heating rate of $1 \mathrm{~K} / \mathrm{s}$. (a) implanted by $0.1 \mathrm{keV}$ helium ions to $5 \times 10^{19} \mathrm{He}^{+} / \mathrm{m}^{2}$ in cold rolled nickel, (b) implanted by $0.15 \mathrm{keV}$ helium ions to $5.0 \times 10^{19} \mathrm{He}^{+} / \mathrm{m}^{2}$ in electron irradiated nickel, and (c) irradiated by $5.0 \mathrm{keV}$ helium ions to $5 \times 10^{19} \mathrm{He}^{+} / \mathrm{m}^{2}$ in well-annealed nickel.

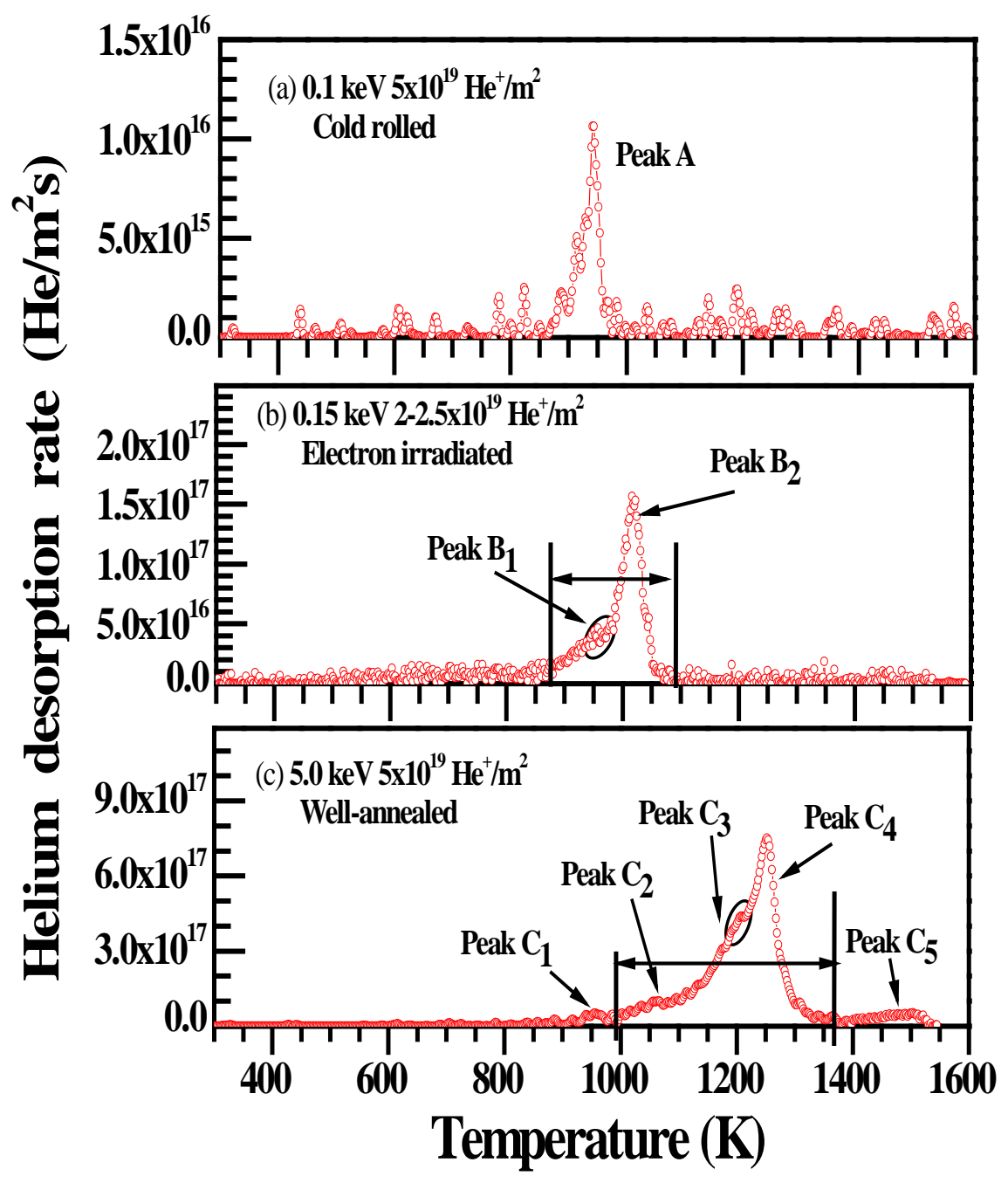


Fig.4. Helium thermal desorption and retention spectra in well-annealed nickel after helium irradiation by $5.0 \mathrm{keV}$ to $5 \times 10^{19} \mathrm{He}^{+} / \mathrm{m}^{2}$. Heating rate is $1 \mathrm{~K} / \mathrm{s}$, (a) was annealed at $1223 \mathrm{~K}$ for 1 hour, and (b) was annealed at $1123 \mathrm{~K}$ for 1 hour.

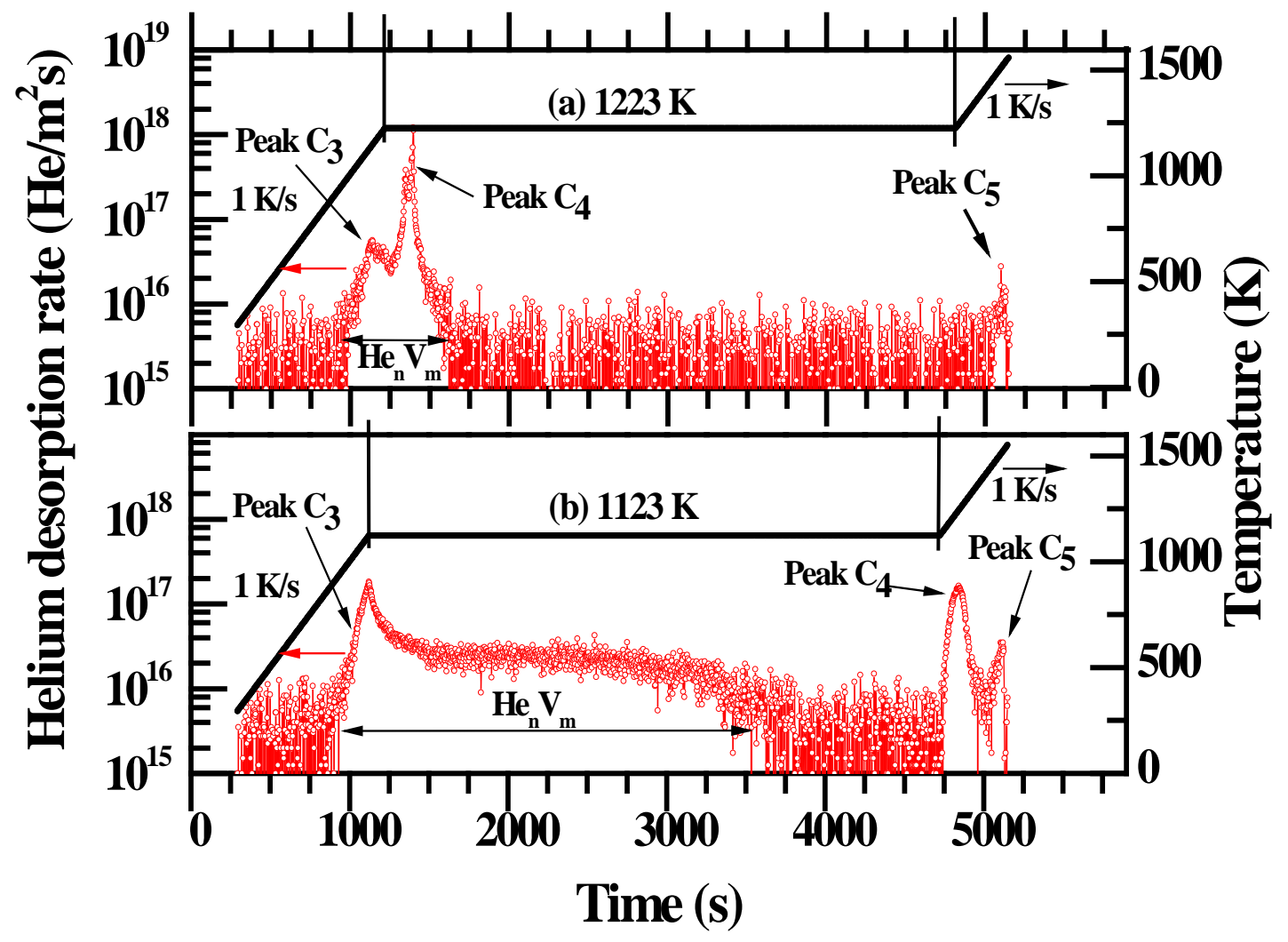


Fig.5. Microstructures in well-annealed nickel: (a) after irradiation by $5.0 \mathrm{keV}$ helium ions to $5 \times 10^{19} \mathrm{He}^{+} / \mathrm{m}^{2}$, (b) heating to $1223 \mathrm{~K}$ with a rate of $1 \mathrm{~K} / \mathrm{s}$, (c) annealing at $1223 \mathrm{~K}$ for 30 minutes.

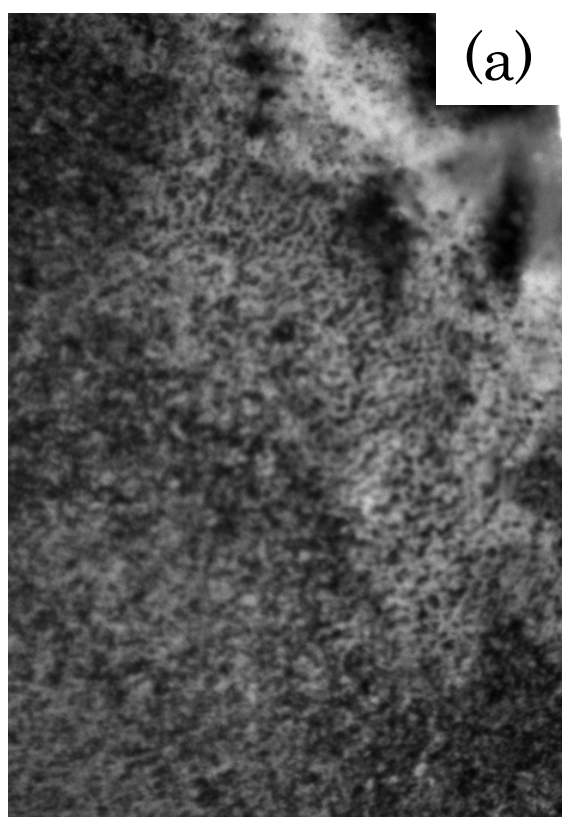

Irradiated by $5 \mathrm{keV} \mathrm{He}^{+}$ $5 \times 10^{19} \mathrm{He}^{+} / \mathrm{m}^{2}$ dose
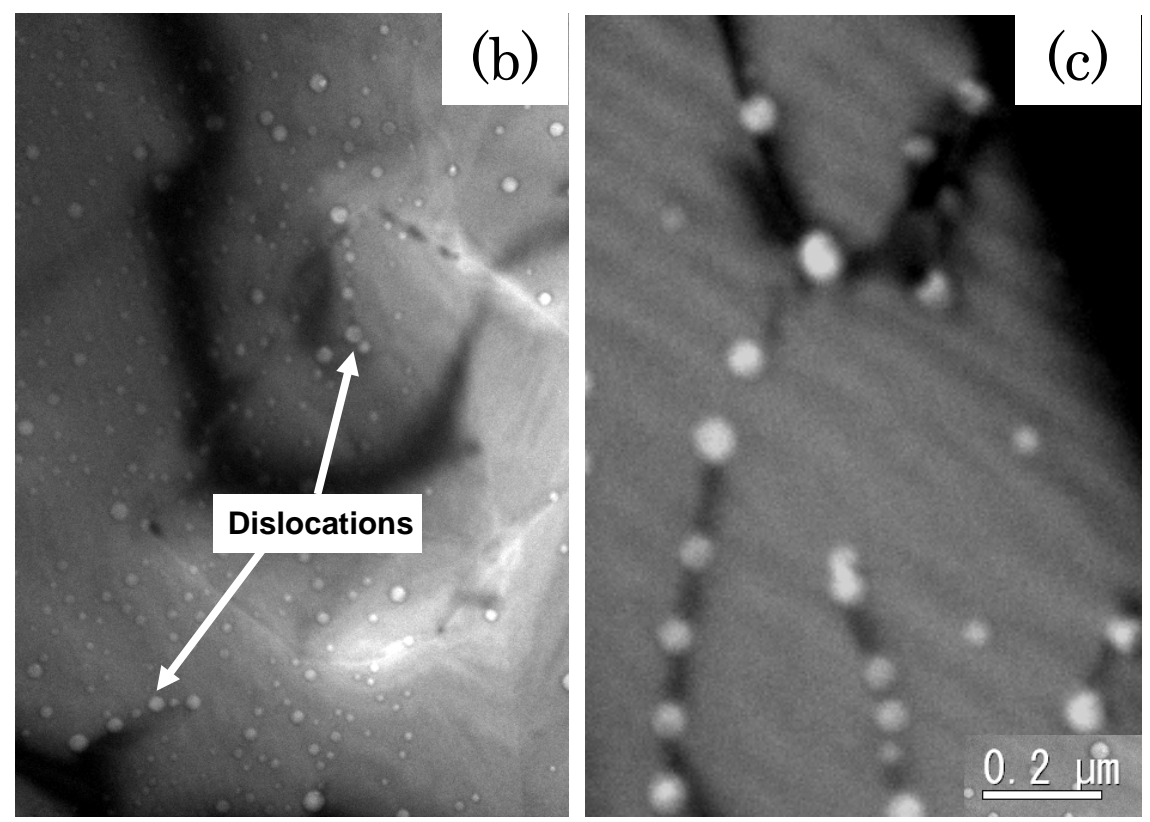

$1223 \mathrm{~K}$

30 minutes

Thermal procedure 
Fig.6. Microstructures in nickel after helium ion irradiation by $5.0 \mathrm{keV}$ to $5 \times 10^{19} \mathrm{He}^{+} / \mathrm{m}^{2}$ : (a) heating to $1123 \mathrm{~K}$ at a rate of $1 \mathrm{~K} / \mathrm{s}$, (b) annealing at $1123 \mathrm{~K}$ for 1 hour, (c) re-heating to $1223 \mathrm{~K}$, and (d) re-heating to $1263 \mathrm{~K}$.

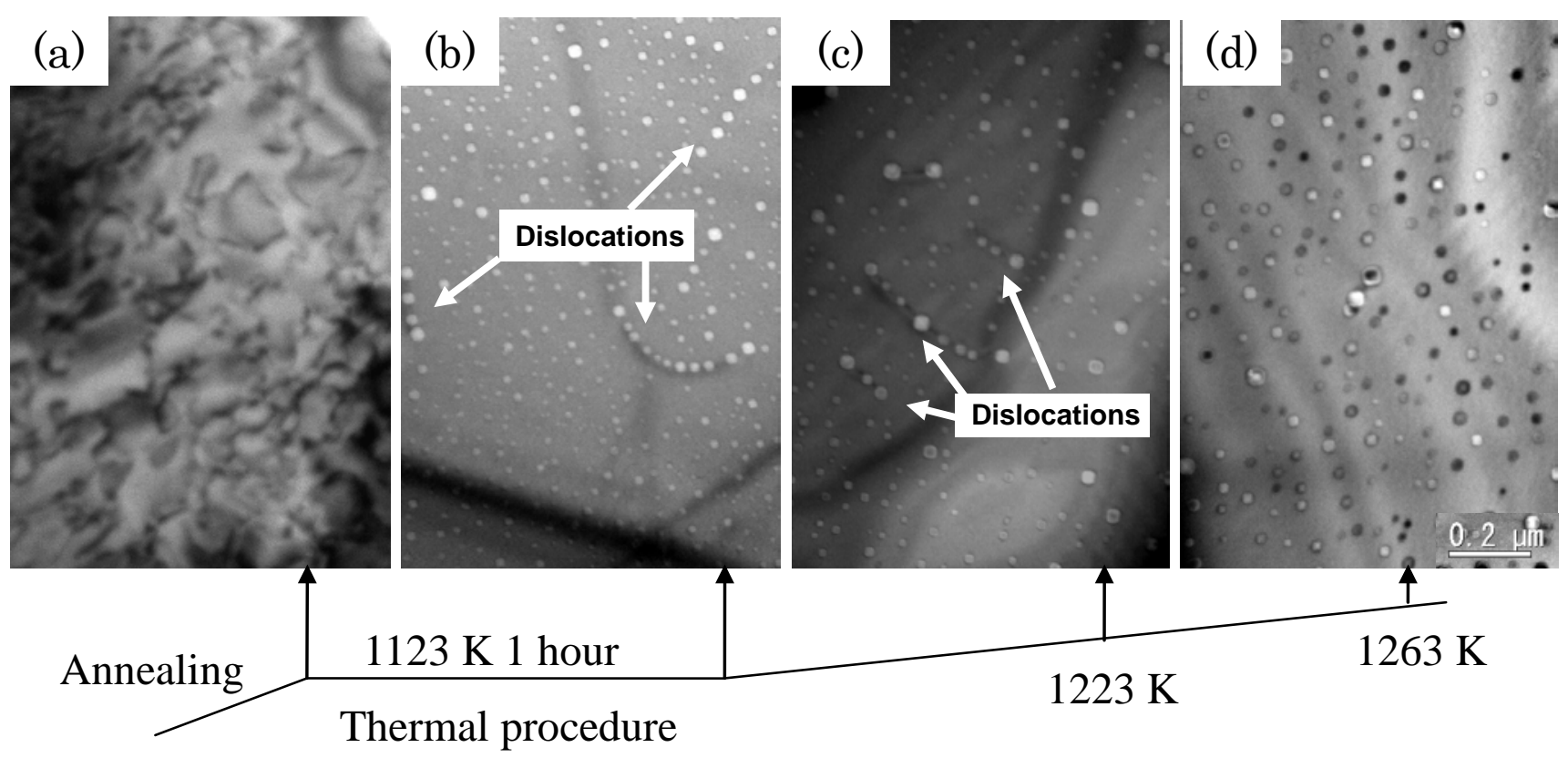

